\title{
Concentration and molecular weight of sodium hyaluronate in synovial fluid from patients with rheumatoid arthritis and other arthropathies
}

\author{
LAURITZ B DAHL, ${ }^{2}$ INGER MARIE S DAHL, 13 \\ ANNA ENGSTRÖM-LAURENT, ${ }^{14}$ AND KIRSTI GRANATH \\ From the ${ }^{1}$ Institute of Medical and Physiological Chemistry, University of Uppsala, Sweden; the ${ }^{2}$ Department \\ of Paediatrics and the ${ }^{3}$ Department of Medicine, University Hospital of Troms $\phi$, Norway; the ${ }^{4}$ Department of \\ Medicine, University Hospital, and the ${ }^{5}$ Department of Polymer Physical Chemistry, AB Pharmacia, \\ Uppsala, Sweden
}

SUMMARY The molecular weight distribution of hyaluronate (HA) in synovial fluid (SF) from 10 patients with rheumatoid arthritis (RA), from six patients with other joint disorders, and from five recently deceased persons without joint affections was investigated by a gel chromatographic procedure. A new and highly specific radioassay was used for determination of the HA concentration in the effluent from the chromatographic column, and this allowed analyses on $0.5 \mathrm{ml}$ or less of untreated synovial fluid. The results confirmed the findings by others that the weight-average molecular weight $\left(\mathrm{M}_{\mathrm{w}}\right)$ of $\mathrm{HA}$ in SF from patients with RA $\left(4.8 \times 10^{6}\right)$ was similar to that in other joint diseases $\left(5.0 \times 10^{6}\right)$ and moderately but significantly $(\mathrm{p}<0.001)$ lower than that of normal SF $\left(7 \cdot 0 \times 10^{6}\right)$. Furthermore, the molecular weight distribution of HA in the pathological SF was generally broad and varied considerably between individuals. The HA concentration in the pathological SF varied between 0.17 and $1.32 \mathrm{~g} / \mathrm{l}$, which is in accordance with previous reports and considerably lower than that of normal SF. Neither the nature of the arthropathy and the extent of the inflammatory process nor the pharmacological treatment had a tendency to influence the HA concentration in the SF, the mean molecular weight of HA, or its molecular weight distribution. Although the concentration of HA in SF drops in joint disease, the total amount of the polysaccharide is greatly enhanced. Also the amount of high molecular weight polysaccharide $\left(M_{w}>6 \times 10^{6}\right)$ is in excess in joint disease. The pathological state is therefore characterised not by lack of high molecular weight hyaluronate but by a dilution of it.

Key words: gel chromatography, radioassay, joint disease.

During the last 20 years several studies have aimed to show a connection between the properties of the hyaluronic acid (sodium hyaluronate, HA) in the synovial fluid (SF) and the severity of joint affections in rheumatoid arthritis (RA). ${ }^{1-5}$ The total amount, concentration, and molecular weight of HA have been investigated, and there is a general agreement that the SF in RA contains a lower concentration of HA $(1.09-1.20 \mathrm{~g} / 1)$ with a lower weight-average molecular weight $\left(1.2-4.5 \times 10^{6}\right)$

\footnotetext{
Accepted for publication 14 May 1985.

Correspondence to Dr Lauritz Dahl, Department of Paediatrics, University Hospital, 9000 Troms $\emptyset$, Norway.
}

than the SF from the normal knee joint (HA concentration 1.45-3.12 g/l; HA $\mathrm{M}_{\mathrm{w}}$ 1.6-10.9 $\times$ $\left.10^{6}\right){ }^{2}$ Increased degradation, incomplete synthesis, and increased production of incompletely polymerised HA have been postulated as possible explanations of these observations. ${ }^{2-4}$

Different methods for the estimation of HA concentration and molecular weights have been used. ${ }^{1-5}$ The HA has usually been isolated from the synovial fluid before the analyses, which introduces the uncertainty of incomplete recovery and possible degradation of the polymer. Most studies have afforded mean molecular weights rather than molecular weight distributions, ${ }^{1-3}$ and in some 
studies control values were lacking. ${ }^{5}$ In the present work we determined the molecular weight distribution of HA in SF by a gel chromatographic technique developed in one of our laboratories. ${ }^{67} \mathrm{~A}$ new assay technique ${ }^{89}$ allowed us to analyse the HA in SF without any prior treatment of the fluid. We used normal joint fluids from deceased patients as controls.

\section{Patients and methods}

\section{PATIENTS}

Twenty-three samples of synovial fluid from 16 patients with different arthropathies and from five recently (within two hours) deceased patients with- out joint disorders were investigated (Table 1$)^{3}$ Patients 15 and 16 were investigated before an after injection of steroids into the knee join Patients 1-10 fulfilled the criteria for RA. ${ }^{10}$ Patients 11-16 had different types of other arthropathie? Patients 17-20 died because of acute myocardig. infarction and patient 21 of traffic accident. Table $\frac{9}{1}$ shows data on sex, age, diagnosis, erythrocyte sedimentation rate (ESR), Waaler-Rose titre, celf and volume of SF, and medical treatment.

SYNOVIAL FLUID

In patients 1-16 arthrocenteses of the knees werg performed for diagnostic or therapeutic purpose and all fluid was collected. The aspirations wer

Table 1 Characterisation of 16 patients with different arthropathies and five patients without arthropathy

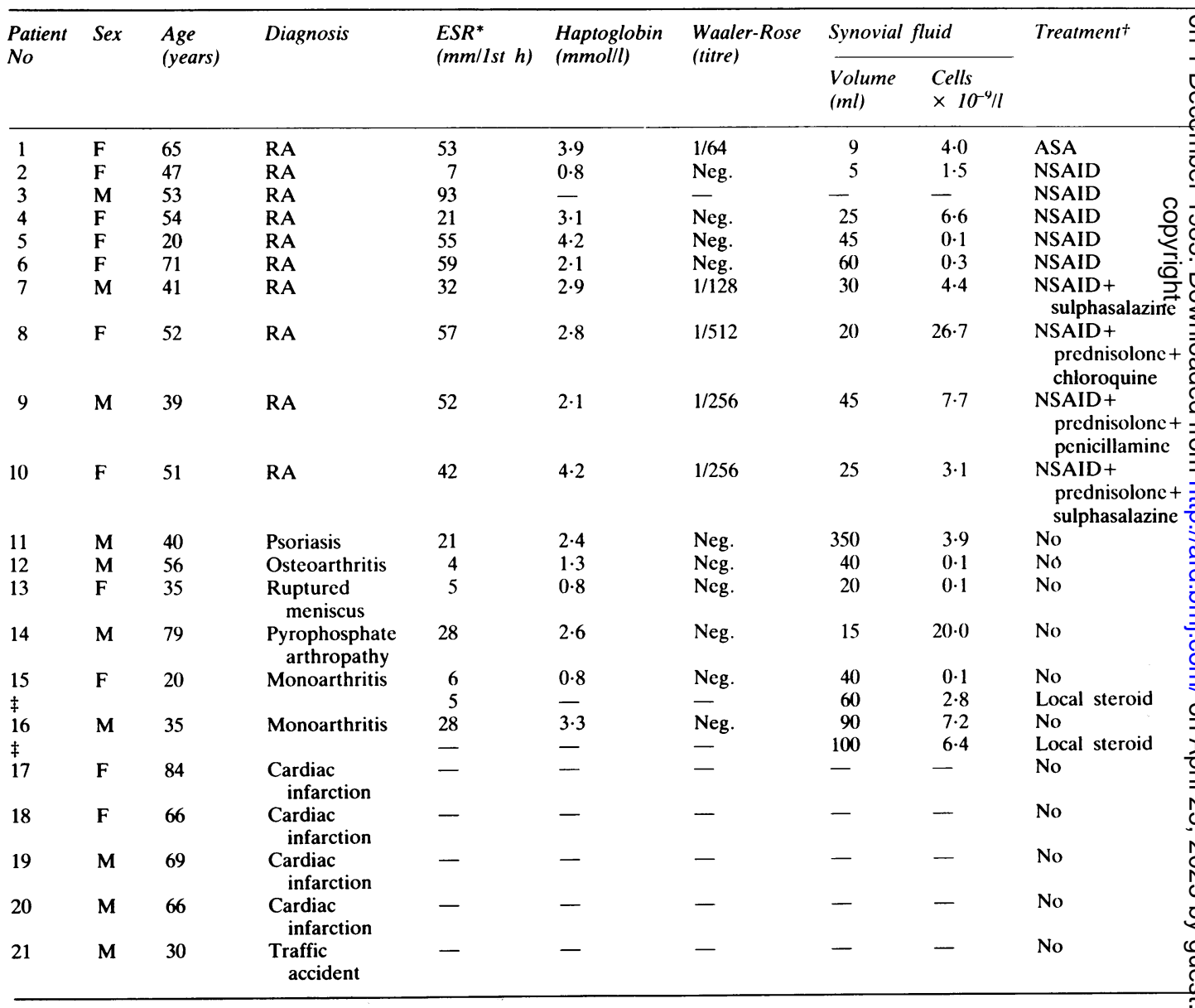

* ESR = erythrocyte sedimentation rate.

$+A S A=$ acetylsalicylic acid; $N S A I D=$ non-steroidal anti-inflammatory drug.

$¥$ Patients 15 and 16 were investigated before and some days after steroid instillation into the knee joint. 
made under sterile conditions and done by one physician with the same technique in all patients. In patients 17-21 the SF was collected shortly after death by gentle instillation of $20 \mathrm{ml}$ of $0.9 \%$ saline into the knee joint, followed by aspiration. In this way sufficient material for chromatography was obtained. When synovial fluid was collected in this manner, however, the determination of HA concentration was precluded. All samples were frozen at $-20^{\circ} \mathrm{C}$ until used.

\section{R A D I O A S S A Y}

HA was analysed as described in detail elsewhere. ${ }^{9}$ Briefly, protein with specific affinity for HA was prepared from cartilage by affinity chromatography and labelled with ${ }^{125}$ I. ${ }^{9}{ }^{11}$ The radioactive protein was incubated in the presence of protease inhibitors with varying amounts of free HA and a fixed amount bound to a Sepharose gel. The protein was allowed to partition between free and bound polysaccharide. The amount of radioactivity pelleted with the gel was a function of the amount of free HA in the system. Standard curves were made with pure HA (Healon) in the range of 2-2000 ng. This assay has a standard error in biological fluids of $15-20 \%{ }^{9}$

\section{DETERMINATION OF MOLECULAR WEIGHT D I S T R I B U T I O N S}

Calibrated gel chromatography was used to fractionate HA and determine its molecular weight distribution. ${ }^{6}$ Samples of SF up to $0.5 \mathrm{ml}$ were diluted with elution buffer and applied in $1 \mathrm{ml}$ portions to a $1 \times 110 \mathrm{~cm}$ column filled with one part Sepharose CL-4B (Pharmacia Fine Chemicals, Uppsala, Sweden) and two parts a cross-linked $0.5 \%$ agarose (Pharmacia; not commercial). The column was operated at $20 \pm 1^{\circ} \mathrm{C}$ at a constant flow rate of $15 \mathrm{ml} / \mathrm{h}$, and $1 \mathrm{ml}$ fractions were collected. The eluent was $0 \cdot 15 \mathrm{M} \mathrm{NaCl} / 0.02 \quad \mathrm{M} \mathrm{Na}_{2} \mathrm{~B}_{2} \mathrm{O}_{7}$ adjusted to $\mathrm{pH} 11 \cdot 6$. HA in the eluate was determined by radioassay. The recovery in the eluate of the total amount applied was $88 \pm 12$ (SD) \%. The elution profile was translated into a molecular weight distribution with the aid of a calibration

Table 2 Concentration and average molecular weights of sodium hyaluronate in synovial fluid from the knee joints of 16 patients with different arthropathies and five patients without joint disorders

\begin{tabular}{|c|c|c|c|c|}
\hline \multirow[t]{2}{*}{ Patient No } & \multirow[t]{2}{*}{$H A$ concn. $(g / l)$} & \multirow[t]{2}{*}{ Total HA in joint ( $\mathrm{mg})$} & \multicolumn{2}{|c|}{ HA molecular weight } \\
\hline & & & $M_{\mathbf{n}} \times 10^{-\infty}$ & $M_{n} \times 10^{n}$ \\
\hline 1 & $0 \cdot 19$ & $1 \cdot 7$ & $6 \cdot 8$ & $2 \cdot()$ \\
\hline 2 & $1 \cdot 26$ & $6 \cdot 3$ & $4 \cdot 3$ & 0.5 \\
\hline 3 & $0 \cdot 64$ & - & $4 \cdot 3$ & $0 \cdot 3$ \\
\hline 4 & 0.94 & $23 \cdot 5$ & $6 \cdot 3$ & 0.9 \\
\hline 5 & 0.50 & $22 \cdot 5$ & $3 \cdot 2$ & $0 \cdot 3$ \\
\hline 6 & 0.93 & $55 \cdot 8$ & $3 \cdot 6$ & $0 \cdot 3$ \\
\hline $1-6$ mean $\pm S D$ & $0.74 \pm 0.38$ & & $4 \cdot 8 \pm 1 \cdot 5$ & $0.7 \pm 0.7$ \\
\hline 7 & $0 \cdot 86$ & $25 \cdot 8$ & $5 \cdot 5$ & 0.7 \\
\hline 8 & 0.59 & $11 \cdot 8$ & $4 \cdot 5$ & $0 \cdot 4$ \\
\hline 9 & 1.09 & $49 \cdot 0$ & $4 \cdot 6$ & 0.3 \\
\hline 10 & 0.99 & $24 \cdot 8$ & $4 \cdot 5$ & 0.4 \\
\hline $7-10$ mean $\pm S D$ & $0 \cdot 88 \pm 0 \cdot 22$ & & $4 \cdot 8 \pm 0 \cdot 5$ & $0 \cdot 4 \pm 0 \cdot 2$ \\
\hline $1-10$ mean $\pm S D$ & $0 \cdot 80 \pm 0 \cdot 32$ & & $4 \cdot 8 \pm 1 \cdot 1$ & $0 \cdot 6 \pm 0 \cdot 5$ \\
\hline 11 & $1 \cdot 32$ & 462 & $2 \cdot 8$ & $0 \cdot 3$ \\
\hline 12 & $0 \cdot 91$ & $36 \cdot 4$ & $4 \cdot 2$ & $0 \cdot 3$ \\
\hline 13 & 1.00 & $20 \cdot 0$ & $5 \cdot 4$ & 0.7 \\
\hline 14 & 0.43 & $6 \cdot 5$ & $5 \cdot 0$ & 0.5 \\
\hline 15 & $1 \cdot 14$ & $45 \cdot 6$ & 3.9 & 0.5 \\
\hline$\dagger$ & $1 \cdot 26$ & $75 \cdot 6$ & $4 \cdot 0$ & 0.5 \\
\hline 16 & $0 \cdot 17$ & $15 \cdot 3$ & $7 \cdot 9$ & $2 \cdot 2$ \\
\hline$\dagger$ & $0 \cdot 19$ & $19 \cdot 0$ & $6 \cdot 6$ & 0.9 \\
\hline $11-16$ mean $\pm S D$ & $0.80 \pm 0.47$ & & $5 \cdot 0 \pm 1 \cdot 6$ & $0 \cdot 7 \pm 0.6$ \\
\hline 17 & - & - & $6 \cdot 6$ & 0.7 \\
\hline 18 & - & - & $6 \cdot 3$ & $1 \cdot 4$ \\
\hline 19 & - & - & $7 \cdot 1$ & $2 \cdot 7$ \\
\hline 20 & - & - & $7 \cdot 6$ & 1.9 \\
\hline 21 & - & - & $7 \cdot 2$ & $2 \cdot 6$ \\
\hline $17-21$ mean $\pm S D$ & & & $7 \cdot 0 \pm 0 \cdot 5$ & $1 \cdot 9 \pm 0 \cdot 8$ \\
\hline
\end{tabular}

- In a polydisperse macromolecular material the weight-average molecular weight, $M_{w}=\Sigma w_{i} M_{i}, w_{h}$ re $w_{i}$ is the weight fraction of the species with molecular weight $\mathbf{M}_{i}$. Similarly the number-average molecular weight. $\mathbf{M}_{n}=1 / \Sigma w_{i} / \mathbf{M}_{i}$.

${ }^{\dagger}$ Patients 15 and 16 were investigated before and some days after steroid instillation into the knee joint. 
curve constructed from the elution of well defined calibration fractions. Calculations of the entire distribution and of weight-average $\left(\mathrm{M}_{\mathrm{w}}\right)$ and number-average $\left(M_{n}\right)$ molecular weights were carried out by computer. ${ }^{67}$

\section{STATISTICAL ANALYSIS}

Student's $t$ test was applied in the statistical analysis of the data.

\section{Results}

CONCENTRATION OF HYALURONATE IN SYNOVIAL FLUID

Analyses of samples of SF from patients with arthropathies are summarised in Table 2. The HA concentration varied between $0 \cdot 17$ and $1.32 \mathrm{~g} / \mathrm{l}$. The patients with RA had concentrations within the same range as patients with other arthropathies. The mean concentration of HA was similar in patients treated with non-steroidal anti-inflammatory drugs (NSAID) alone and those who in addition had received prednisolone or other potent drugs (Table 1). The concentration of HA did not change after local steroid therapy, measured in two patients (15 and 16).
MOLECULAR WEIGHT OF HYALURONATE The molecular weight distributions of HA for some of the patients are shown in Fig. 1. The polysacchat: ide showed a broad distribution in all samples, witff molecular weights in the range of $4 \times 10^{4}$ to $6 \times 10$ ? A great variation of the distribution was foung within each group of patients. In all fluids the part $\$$ the total HA with molecular weight $>6 \times 10^{6}$ was greater than $30 \% . \mathrm{M}_{\mathrm{w}}$ values of between $2.8 \times 10 \%$ and $7.9 \times 10^{6}$ were recorded (Table 2). The means of the molecular weights of HA in SF from five deceased patients without arthropathy $\left(M_{w} 7.0 \chi_{.}\right.$ $10^{6} ; M_{n} 1.9 \times 10^{6}$ ) were moderately but significantl ( $p<0.001$ and $p<0.01$ respectively) higher than the mean values of the samples from patients with $R$ $\left(M_{w} 4.8 \times 10^{6} ; M_{n} 0.6 \times 10^{6}\right)$. Patients with other arthropathies showed molecular weight distributions and mean molecular weights in the same range as the patients with RA $\left(M_{w} 5.0 \times 10^{6} ; M_{n} 0.7 \times 10^{6}\right.$ d (Table 2). The mean molecular weight was not. different in the rheumatic patients (Nos 7-10) treated with NSAID and prednisolone or othe drugs compared with patients (Nos 1-6) treated wit $B$ NSAID alone. There was no change in the molecip lar weight distribution of HA in the SF before and after treatment with local steroids, measured in $8 v$ patients (Nos 15 and 16).

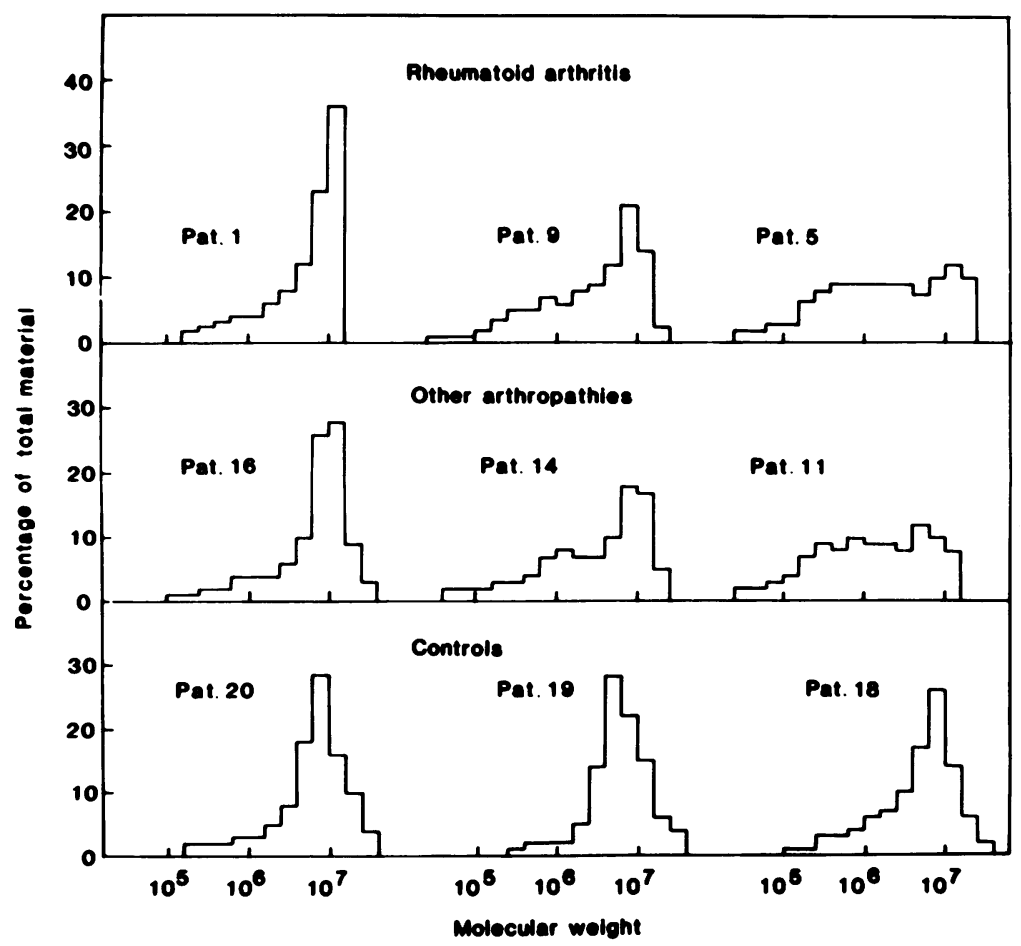

Fig. 1 Molecular weight distributions for sodium hyaluronate from synovial fluid o $\dot{\vec{B}}$ some patients (a) with rheumatoido arthritis; (b) with other arthropathies; and (c) without joint disease. The patient numbers correspond to those found in Tables 1 and 2. The patients were selected to show the full variation of molecular weight distributions $\mathrm{N}$ observed in each group. 


\section{Discussion}

The methodology used in this work has a major advantage over techniques used by other authors, i.e., the analyses can be made on small samples of SF without prior purification of the HA. Furthermore, the gel chromatographic technique gives the complete molecular weight distribution, whereas other techniques only produce average molecular weights. Gel chromatography was also used by Bjelle, Andersson, and Granath, ${ }^{5}$ but they were forced to purify the HA by density gradient centrifugation before the analysis.

In order to prove a change in molecular weight of HA in RA it is necessary to analyse a normal reference material by the same technique. It is evident from the fact that the human knee joint contains only a few millilitres of SF that there are both practical and ethical obstacles to the collection of material in vivo. Most studies report results from SF collected after death, which introduces the uncertainty of postmortem changes. If material is collected as soon as possible after death we believe that our results are representative of normal SF, and this conclusion is reinforced by the close similarity between our molecular weight data and those obtained by Balazs et al. ${ }^{2}$ on HA from volunteers. The latter authors also showed that HA removed from the joint by a washing procedure had the same properties as HA isolated from undiluted SF.

The concentration of HA in the SF in RA and other joint disorders (Table 2) was of the same order as or sometimes even lower than values reported by others $^{1-3}$ and clearly lower than the concentration reported in normal fluids. ${ }^{2}$ The total amount of HA in the joint calculated from the volume of SF (Table 1 ) and the concentration of HA (Table 2) varied considerably in the range 1.7 to $462 \mathrm{mg}$ (Table 2) (mean $53 \mathrm{mg}$; median $23.5 \mathrm{mg}$ ) but was generally higher than that found by Balazs et al. ${ }^{2}$ in healthy volunteers $(2.03 \pm 0.40 \mathrm{mg}$ in directly aspirated fluid and $1.71 \pm 0.53 \mathrm{mg}$ in subsequent washings).

The mean value of the molecular weight of HA in joint disease is moderately although significantly lower than in normal SF (Table 2), and our data thus confirm previous reports. ${ }^{1-4}$ However, it is striking that despite severe arthropathy the amount of very high molecular weight $\mathrm{HA}$ is considerable; as a matter of fact, in view of the total increase of $\mathrm{HA}$ in the joint there is more high molecular weight polysaccharide $\left(M_{w}>6 \times 10^{6}\right)$ in an inflamed joint than in a normal joint. It has often been claimed that the change in rheological properties of the synovial fluid in RA is due to lack of high molecular weight HA. Our data are at variance with such an interpretation; the main cause of decreased vis-

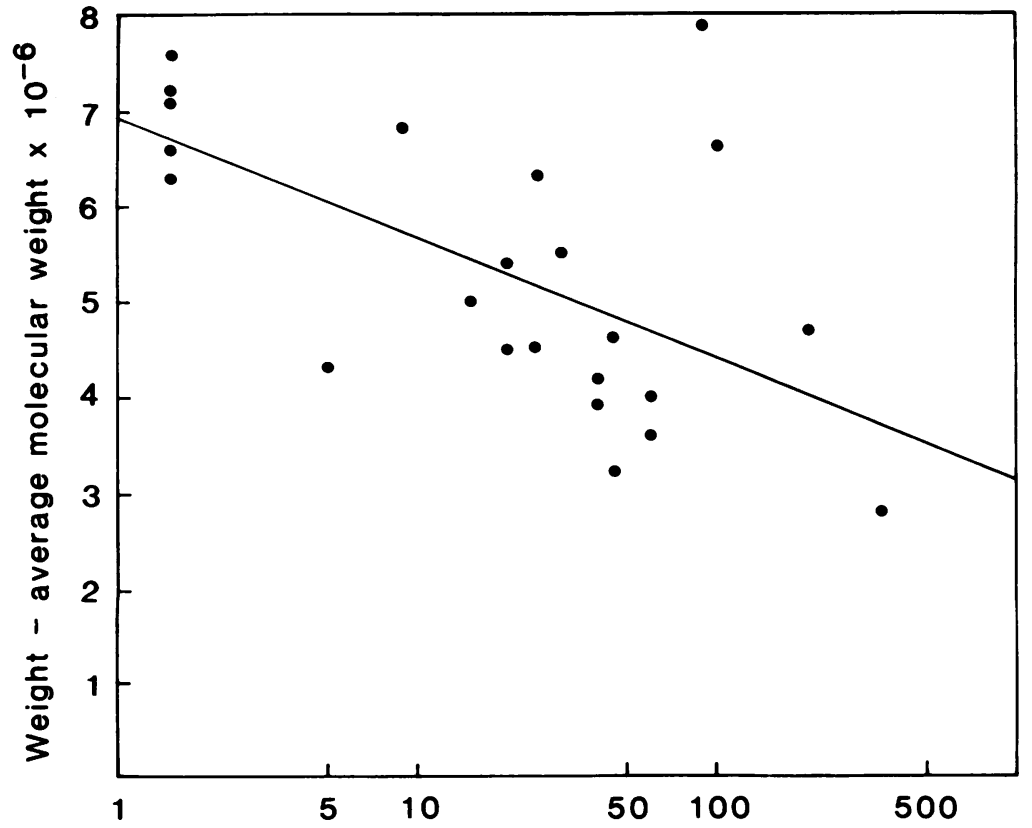

Volume of synovial effusion ( $\mathrm{ml}$ )
Fig. 2 Plot of the weight-average molecular weight of sodium hyaluronate versus logarithm of the volume of synovial fluid in the joint. The correlation coefficient $r=-0.58$. The volume of the synovial fluid of the controls was set to $1.5 \mathrm{ml}$. 
coelastic behaviour must be the lower concentration of the polysaccharide. ${ }^{12}$

We found that systemic or local steroid treatment had no effect on the concentration or molecular weight of HA. Others have found a possible effect of steroids on the property of HA in SF. ${ }^{13} \mathrm{We}$ found no correlation between the HA concentration or the molecular weight and the clinical and laboratory parameters shown in Table 1, except for a negative correlation between the weight-average molecular weight and the effusion volume (Fig. 2).

High molecular weight $\mathrm{HA}$ has been used for local treatment in joint disease in humans and animals. ${ }^{14-17}$ The rationale for this treatment has been to replace degraded HA with high molecular weight polysaccharide. Our present data show that high molecular weight $\mathrm{HA}$ is not lacking in the disordered joint. The therapeutic effect of injected high molecular weight HA may therefore be due to an increase in the local concentration rather than a major change in the macromolecular properties of the synovial polysaccharide.

The authors are deeply indebted to Professor Torvard Laurent for valuable discussions and help with the manuscript. We also want to acknowledge the skilful assistance given by Toomas Kiiver and Karin Lilja. The project was supported by grants from the Swedish Medical Research Council, Gustaf the Vth 80-year birthday fund, the Swedish Association against Rheumatism, and AB Pharmacia.

\section{References}

1 Seppälä P. Synovial fluid in rheumatoid arthritis. Turku: University of Turku, 1964. (Thesis.)

2 Balazs E A, Watson D, Duff I F, Roseman S. Hyaluronic acid in synovial fluid. Molecular parameters of hyaluronic acid in normal and arthritic human fluids. Arthritis Rheum 1967; 10: 357-76.

3 Sundblad L. Glycosaminoglycans and glycoproteins in synovial fluid. In: Balazs E A, Jeanloz R W, eds. The amino sugars. New York and London: Academic Press, 1965; 11A: 229-50.

4 Barker S A, Bayyuk S H I, Brimacombe J S, Hawkins C F, Stacey M. Fingerprinting the hyaluronic acid component of normal and pathological synovial fluids. Clin Chim Acta 1963; 8: $902-9$.

5 Bjelle A, Andersson T, Granath K. Molecular weight distribution of hyaluronic acid of human synovial fluid in rheumatic diseases. Scand J Rheumatol 1983; 12: 133-8.

6 Wik K O, Andersson T, Jacobsson J Ö, Granath K A.尺 Physicochemical characterization of hyaluronate. In: Wik K O.d Physicochemical studies on hyaluronate [Thesis]. Uppsala: Acta Univ Upsaliensis Uppsala, 1979, No. 334.

7 Laurent U B G, Granath K A. The molecular weight of hyaluronate in aqueous humour and vitreous body of rabbit and $\vec{\overrightarrow{ }}$ cattle eyes. Exp Eye Res 1983; 36: 481-92.

8 Tengblad A. Quantitative analysis of hyaluronate in nanogram amounts. Biochem J 1980; 185: 101-5.

9 Laurent U B G, Tengblad A. Determination of hyaluronate in' biological samples by a specific radioassay technique. Anat Biochem 1980; 109: 386-94.

10 Ropes M W, Bennett G A, Cobbs S, Jacox R, Jessar R A. 195800 revision of diagnostic criteria for rheumatoid arthritis. Bull Rheum Dis 1958; 9: 175-6.

11 Tengblad A. Affinity chromatography on immobilized hyalur-은 onate and its application to the isolation of hyaluronate binding proteins from cartilage. Biochim Biophys Acta 1979; 578: 281-9.

12 Gibbs D A, Merrill E W, Smith K A, Balazs E A. Rheology of hyaluronic acid. Biopolymers 1968; 6: 777-91.

13 Näntö V, Seppälä $P$, Kulonen E. Effect of hydrocortisone administration on the hyaluronic acid fractions of synovial fluid只 in rheumatoid arthritis. Clin Chim Acta 1962; 7: 794-9.

14 Rydell N W, Butler J, Balazs E A. Hyaluronic acid in synotal fluid. VI. Effect of intra-articular injection of hyaluronic acidsncr the clinical symptoms of arthritis in track horses. Acta Vet Scō 1970; 11: 139-55.

15 Peyron J G, Balazs E A. Preliminary clinical assessment of Na-hyaluronate injection into human arthritic joint. Pathol Biof (Paris) 1974; 22: 731-6.

16 Åsheim $\AA$, Lindblad G. Intra-articular treatment of arthritis in race-horses with sodium hyaluronate. Acta Vet Scand 1976; 17:0 379-94.

17 Wigren A, Falk J, Wik O. The healing of cartilage injuries under the influence of joint immobilization and repeated hyaluronic acid injections. An experimental study. Acta Orthop Scand 1978; 49: 121-33. 